\title{
PAPER
}

\section{Limb length and dementia in an older Korean population}

\author{
J-M Kim, R Stewart, I-S Shin, J-S Yoon
}

J Neurol Neurosurg Psychiatry 2003;74:427-432

See end of article for authors' affiliations

.....................

Correspondence to:

Professor J-S Yoon,

Department of Psychiatry,

Chonnam National

University Medical School,

5 Itak-dong, Dong-ku,

Gwangiu 501-746,

Republic of Korea;

isyoon@chonnam.ac.kr

Received

28 October 2002

Accepted in revised form

21 December 2002

\begin{abstract}
Objectives: There has been little research into risk factors for dementia outside Western settings, in particular the importance of early life nutrition as estimated by adult body size. This study investigated the associations of arm and leg length with cognitive impairment and dementia in a community sample of older Korean people.

Methods: 746 community residents aged 65 or over were clinically assessed for dementia and cognitive impairment. The following were also measured: arm length (demispan), leg length (iliac crest height), and sitting height (standing height minus iliac crest height). Reproductive history was also ascertained in women.

Results: Shorter demispan and leg length were associated with increased age and lower education. They were also associated with dementia and Alzheimer's disease after adjustment for these factors. These associations were only significant in women but were not explained substantially by timing of the menarche or menopause. The association between lower education and dementia was also stronger in women, but was not explained substantially by limb length.

Conclusions: Shorter limb length was associated with lower childhood socioeconomic status, as estimated by the presence/duration of formal education. It was also independently associated with dementia and Alzheimer's disease. Sex differences in this association might be explained by gender disadvantage in early life for this cohort or by different associations with health states (for example, cardiovascular disease) later in life.
\end{abstract}

$\mathrm{T}$ here has been increasing interest in aspects of the early life environment as aetiological factors for late life cognitive impairment and dementia. Lower education has been found to be associated with increased risk of dementia in numerous studies of developed nation populations, ${ }^{12}$ as well as in some non-Western settings. ${ }^{3}$ Other early life factors found to be associated with dementia have included area of residence, ${ }^{45}$ parental occupation, ${ }^{6}$ and household size. ${ }^{6}$ Maturation of the brain, which occurs to its greatest extent during the first three years of life and continues for the first two decades, ${ }^{7}$ progresses in parallel with skeletal growth. An adverse early life environment, in particular poor nutrition, affects growth and development, ${ }^{8}$ and may be associated with an increased risk of cognitive impairment and dementia in later life. Decreased head circumference ${ }^{9}$ and adult height ${ }^{10}$ have been found to be associated with cognitive impairment or dementia, or both, but overall there has been little research in this area. Standing height is affected by degenerative processes in older people, particularly osteoporotic kyphosis, ${ }^{11}$ and limb length measurements provide a more accurate representation of earlier stature. Furthermore, there is some evidence to suggest that limb length is more strongly associated than trunk height with socioeconomic factors in childhood, as well as with later mortality and cardiovascular disease. ${ }^{12}$

Most dementia research has focused on developed Western populations. Rapid demographic aging is occurring in many other nations and dementia is becoming increasingly an important public health issue. The impact of poor nutrition in childhood is an important concern, but has received little research. In collaboration with the 10/66 Dementia in Developing Countries Research Program, ${ }^{13}$ a community survey of psychiatric morbidity was carried out in Kwangju, South Korea in 2001. We hypothesised that dementia would be associated with decreased limb length, that this would be independent of education, and that limb length would, at least in part, account for the association between dementia and lower education.

\section{METHODS}

Study population

The sampling frame for this study was all inhabitants aged 65 or over recorded in national residents registration lists within two defined geographical areas (one urban, one rural) of Kwangju, South Korea in 2001. There are no long term care facilities in these catchments. An accurate entry on national registration lists is a legal requirement in Korea and is necessary for many aspects of daily life, including pension provision. A letter explaining the purpose of study was sent to all eligible older people. All participants gave informed consent, and the study was approved by the appropriate research ethics committee.

\section{Assessments and measurements}

The survey was carried out with two recruitment phases: (1) Sixteen graduate level research assistants, trained and supervised by the project psychiatrist, carried out home based interviews. Information was gathered from participants and their family members using a structured questionnaire. This included the Geriatric Mental State Interview (GMS) with diagnoses of organic brain syndrome and depression assigned using the AGECAT computerised algorithm. ${ }^{14}(2)$ At a second interview (attempted in all participants), anthropometric measurements were taken and a clinical diagnosis of dementia was established by two teams of Korean professionals, consisting of a psychiatrist, a senior nurse, and a psychologist. At both stages, home visits were repeated on at least two occasions if no contact was made. The mean (SD) interval between the two interviews was 9 (5.4) days. People who completed both interviews comprise the sample for the analysis presented here.

\section{Anthropometric measures}

There are various measurements that have been used to quantify limb length. Arm length has been measured by total arm $\operatorname{span}^{15}$ or demispan. ${ }^{16}$ Leg length has been measured by knee height, ${ }^{17}$ iliac crest height, ${ }^{18}$ or estimated by subtracting sitting 
from standing height. ${ }^{19}$ For the purposes of this study, arm length (demispan) was measured from the web between the third and fourth finger along the outstretched arm to the sternal notch. Leg length (iliac crest height) was measured from the uppermost part of the iliac crest to the ipsilateral lowest part of the lateral malleus. Both were measured using a plastic tape measure and on the left arm or leg unless they had been affected by disease or disability. Standing height was measured from heel to vertex and "sitting height" was derived by subtracting the leg length from this.

\section{Data on early life environment}

The following information was gathered from participants using a structured questionnaire (corroborated by family members where possible): birth order, number of siblings, parental occupation (manual or non-manual), area of residence before age 20 (urban or rural), and duration of formal education.

\section{Reproductive history}

In female participants, the following information was obtained: age of menarche, number of children, age at first childbirth, and age of menopause.

\section{Other independent variables}

Age, sex, self reported hypertension, and diabetes. In those who agreed, blood was also taken and analysed for apolipoprotein E (APOE) genotype.

\section{Cognitive assessment and dementia diagnosis}

Cognitive function was assessed using the Korean version of Mini-Mental State Examination (MMSE-K), ${ }^{20}$ and the memory subscale of the Korean Dementia Rating Scale (KDRS). ${ }^{21}$ Cognitive impairment was defined as MMSE-K scores of 20 or below. ${ }^{22}$ The KDRS is derived from the Mattis Dementia Rating Scale, ${ }^{23}$ translated and modified for use in Korea. The Instrumental Activities of Daily Living Scale $(\mathrm{IADL})^{24}$ and Clinical Dementia Rating (CDR ${ }^{25}$ were administered. Of the participants, $64 \%$ had previously participated in a survey two years earlier with similar measurements administered including MMSE-K and KDRS. ${ }^{26}$ Changes in the scale scores were taken into account when making diagnoses. Information on past history and present illness, and family history of dementia was gathered from participants and their family members. A physical examination including blood pressure measurement (by the senior nurse) and neurological examination (by the psychiatrist) were performed. On the basis of the above information, consensus diagnoses of dementia and dementia subtypes were made by three psychiatrists and a psychologist. Dementia, Alzheimer's disease, and vascular dementia diagnoses were made according to DSM-IV, ${ }^{27}$ NINCDS-ADRDA, ${ }^{28}$ and NINDS-AIREN criteria, ${ }^{29}$ respectively. The organic brain syndrome category from the GMS interview was not a dependent variable in the final analysis but was used to assess the effect of differential attrition between interviews, as data were complete for this measure in all first interview participants.

\section{Data analysis}

Single explanatory variable analyses were carried out to investigate (a) factors associated with dementia, (b) factors associated with anthropometric measurements, and (c) the association of interest between anthropometric measurements and dementia. These associations were further analysed using stepwise logistic regression models to investigate confounding/mediation. Because of wide sex differences in measurement distributions, in the nature of the measurements (for example, iliac crest height) and, potentially, in their associations with other factors, interaction with sex was investigated in multivariable analyses. Ages at menarche and menopause were considered as potential mediating factors in women. Analyses were repeated for dementia subtypes as dependent variables. Further exploratory analyses investigated associations between anthropometric measurements and potential mediating factors, including cognitive function within the "normal" range (defined as MMSE-K>23), ${ }^{22}$ hypertension, and diabetes. Finally, anthropometric measures were considered as potential confounding factors for the association between education and dementia.

\section{RESULTS}

Of 1566 residents aged 65 or over identified from registration lists, $1204(77 \%)$ completed the first interview with research assistants. Of the remainder, contact could not be established with $195(12 \%), 71(5 \%)$ did not wish to participate, 55 (4\%) had no fixed abode, 28 (2\%) had changed address, and 9 ( $1 \%)$ had died before the visit. Participants and non-participants at this stage did not differ significantly with respect to age (mean ages 72.2 and 72.4 respectively), or sex (58\% and $62 \%$ female respectively). For participants who had participated in the previous survey, we found no evidence of practice effects for the MMSE as scores for this group were lower than those for new participants (mean difference 1.5 points).

Of first interview participants, $746(62 \%)$ participated in the second interview. Of the remainder, contact could not be established with $321(27 \%), 92(8 \%)$ refused, four had died in the interval $(<1 \%)$, and data were missing for $41 \quad(3 \%)$. Between interview attrition was associated with increased age (odds ratio (OR) per year increase $1.02,95 \%$ CI 1.00 to 1.04 ), decreased education (OR per year of education $0.97,0.95$ to 1.00), and GMS organicity caseness (OR 1.49, 1.16 to 1.93) but not significantly with sex (OR for women 1.07) or GMS depression caseness (OR 1.13). The strength of association between GMS organicity and education in all participants at the first interview (OR per year of education 0.80) was similar to that in participants at the second interview (0.81). The principal reason for attrition was that the person was away from home at the time of research visits despite repeated attempts to make contact.

Of the 746 participants in both interviews, $110(15 \%)$ were diagnosed as having dementia. Of these, $87(79 \%)$ were diagnosed as having Alzheimer's disease, 15 (14\%) had vascular dementia, and eight $(7 \%)$ had dementia of other aetiology. One hundred and eighty six (25\%) of the participants were classified as having cognitive impairment without dementia. Data on APOE genotype were available in 699 participants (94\%).

Dementia was significantly associated with increased age, female sex, lower education, and APOE e4 (table 1). No evidence was found for non-linearity in the association between age and dementia. In women, dementia was associated with older age at menarche and younger age at menopause.

For the total sample, the mean (SD) value for demispan was $79.3(5.1) \mathrm{cm}$, for leg length $86.4(5.4) \mathrm{cm}$, and for sitting height $69.4(6.0) \mathrm{cm}$. The Pearson's correlation coefficient between demispan and leg length was 0.73 , between demispan and sitting height 0.53 , and between leg length and sitting height 0.23 . All measurements were significantly reduced in older participants, in women, and in those reporting lower levels of education (table 2). Decreased leg length was associated with later menarche and menopause. Decreased sitting height was associated with earlier menopause. No associations were found between any of the anthropometric measures and APOE genotype, birth order, number of siblings, parental occupation, or area of residence in early life ( $p$ values $>0.1$ ). In women there were no associations between any of the measurements and number of children or age at first childbirth $(\mathrm{p}>0.1)$. 
Table 1 Characteristics of participants by dementia status

\begin{tabular}{llll}
\hline & $\begin{array}{l}\text { No dementia } \\
(n=636)\end{array}$ & $\begin{array}{l}\text { Dementia } \\
(n=110)\end{array}$ & $p$ Value \\
\hline Mean (SD) age (y) & $72.0(5.3)$ & $77.6(6.7)$ & $<0.001$ \\
Sex (\% women) & 56.0 & 74.5 & $<0.001$ \\
APOE e4 genotype (\%) & 14.5 & 31.0 & $<0.001$ \\
Early life environment & $2.5(1.7)$ & $2.5(1.6)$ & 0.8 \\
Mean (SD) birth order & $5.0(2.1)$ & $4.6(1.8)$ & 0.07 \\
Mean (SD) number of siblings & 92.7 & 95.4 & 0.3 \\
Parental manual occupation (\%) & 83.5 & 89.1 & 0.1 \\
Rural residence before age 20 (\%) & 56.6 & 17.8 & $<0.001$ \\
Any formal education (\%) & $16.5(1.7)$ & $17.8(1.3)$ & $<0.001$ \\
Reproductive history in women (n=438) & $5.1(2.1)$ & $5.0(2.2)$ & 0.6 \\
Mean (SD) age at menarche & $21.7(3.4)$ & $21.0(2.4)$ & 0.1 \\
Mean (SD) number of children & $49.6(4.5)$ & $48.2(5.1)$ & 0.022 \\
Mean (SD) age at first child birth & & & \\
Mean (SD) age at menopause & & & \\
\hline
\end{tabular}

Table 2 Factors associated with anthropometric measures

\begin{tabular}{|c|c|c|c|c|c|c|c|}
\hline & Number & $\begin{array}{l}\text { Mean (SD) } \\
\text { demispan }(\mathrm{cm})\end{array}$ & $\mathrm{p}$ Value & $\begin{array}{l}\text { Mean (SD) leg } \\
\text { length }(\mathrm{cm})\end{array}$ & $\mathrm{p}$ Value & $\begin{array}{l}\text { Mean (SD) sitting } \\
\text { height }(\mathrm{cm})\end{array}$ & pValue \\
\hline \multicolumn{8}{|l|}{ Age (y) } \\
\hline $65-69$ & 249 & $80.1(4.8)$ & \multirow[t]{4}{*}{$<0.001$} & $87.3(5.0)$ & \multirow[t]{4}{*}{$<0.001$} & $69.8(5.9)$ & \multirow[t]{4}{*}{0.001} \\
\hline $70-74$ & 232 & $79.7(4.9)$ & & $86.6(5.3)$ & & $69.9(5.8)$ & \\
\hline $75-79$ & 171 & $79.4(5.1)$ & & $86.3(5.4)$ & & $68.9(6.3)$ & \\
\hline $80+$ & 94 & $75.7(5.0)$ & & $83.6(5.9)$ & & $67.2(5.9)$ & \\
\hline \multicolumn{8}{|l|}{ Sex } \\
\hline Male & 308 & $83.4(3.7)$ & \multirow{2}{*}{$<0.001$} & $89.9(4.1)$ & \multirow[t]{2}{*}{$<0.001$} & $74.0(4.9)$ & \multirow[t]{2}{*}{$<0.001$} \\
\hline Female & 438 & $76.4(3.8)$ & & $84.0(4.8)$ & & $66.1(4.4)$ & \\
\hline \multicolumn{8}{|c|}{ Education (y) } \\
\hline 0 & 365 & $77.5(5.0)$ & \multirow[t]{3}{*}{$<0.001$} & $84.6(5.4)$ & \multirow[t]{3}{*}{$<0.001$} & $67.5(5.7)$ & \multirow[t]{3}{*}{$<0.001$} \\
\hline $1-6$ & 263 & $80.2(4.5)$ & & $87.5(4.8)$ & & $70.2(5.8)$ & \\
\hline $7+$ & 118 & $82.8(4.1)$ & & $89.9(4.2)$ & & $73.4(5.3)$ & \\
\hline \multicolumn{8}{|c|}{ Age at menarche in women } \\
\hline-15 & 100 & $77.0(3.3)$ & \multirow[t]{3}{*}{0.4} & $85.4(4.5)$ & \multirow[t]{3}{*}{0.002} & $65.8(3.9)$ & \multirow[t]{3}{*}{0.3} \\
\hline $16-17$ & 211 & $76.6(3.7)$ & & $84.2(4.4)$ & & $65.9(4.4)$ & \\
\hline $18+$ & 127 & $76.3(3.6)$ & & $83.1(5.2)$ & & $66.6(4.4)$ & \\
\hline \multicolumn{8}{|c|}{ Age at menopause in women } \\
\hline-45 & 183 & $77.0(3.4)$ & \multirow[t]{3}{*}{0.3} & $85.3(5.3)$ & \multirow[t]{3}{*}{0.015} & $65.3(3.9)$ & \multirow[t]{3}{*}{0.012} \\
\hline $46-50$ & 182 & $76.6(3.8)$ & & $84.5(4.8)$ & & $65.6(4.8)$ & \\
\hline $51+$ & 73 & $76.2(3.5)$ & & $83.5(4.3)$ & & $66.7(4.1)$ & \\
\hline
\end{tabular}

The odds ratio (OR) for dementia was 2.16 (95\% CI 1.71 to 2.71) for each $5 \mathrm{~cm}$ decrease in demispan, 1.93 (1.56 to 2.39) for each $5 \mathrm{~cm}$ decrease in leg length and 1.30 ( 1.09 to 1.56) for each $5 \mathrm{~cm}$ decrease in sitting height. These associations were present across the distributions for each measure, but particularly noticeable in the lower ranges. For example, the proportion of people with dementia for each quintile of demispan (lowest to highest) were $35.9 \%, 10.9 \%, 11.2 \%, 9.1 \%$, and $6.0 \%$. Patterns of association were similar for leg length and sitting height (data not shown).

For sitting height, no association with dementia was evident after adjustment for age and education (OR per $5 \mathrm{~cm}$ decrease 1.06, 0.87 to 1.29). Multivariable analyses are summarised in table 3 for demispan and leg length as independent variables. Associations between these factors and dementia were diminished in strength but remained statistically significant after adjustment for age and education. However, they seemed to be principally present in women, especially the association between leg length and dementia. Likelihood ratio tests of interaction terms with sex (adjusted for age and education) yielded $p$ values of 0.039 for leg length and 0.14 for demispan. Further adjustment for age of menarche and menopause had little effect on associations in women. On further stratification, there seemed to be sex differences in effect modification by e4. For example, odds ratios for dementia for each $5 \mathrm{~cm}$ decrease in demispan (adjusted for age and education) were 1.26 (0.65 to 2.46$)$ in men without e4 compared with 4.40 (1.02 to 19.0) in men with e4. In women, odds ratios were 1.70 ( 1.06 to 2.74 ) in those without e4 compared with 1.40 (0.66 to 2.94$)$ in those with e4. Interaction terms however did not approach significance.

Associations between leg length and dementia subtypes are summarised in table 4. Associations with Alzheimer's disease and vascular dementia were broadly comparable in strength and showed similar gender interaction, being strongest in women for both limb length measures. Numbers in the "other" dementia group were too small to be analysed. Results for demispan were similar (data not shown). For participants with dementia, leg length and demispan were not significantly associated with IADL or CDR scores ( $p$ values $>0.1$ ).

Further secondary analyses were carried out to investigate potential mediating factors. No significant associations were found between limb length measurements and MMSE-K scores in a subsample with "unimpaired" function (MMSE-K $>23$ ) or with reported hypertension or diabetes in the total sample. Finally the effect of adjustment for limb length on the association between lower education and dementia was investigated in logistic regression analyses (table 5). Lower education (no formal schooling), like the limb length measures, was more strongly associated with dementia in women. However, odds ratios were not substantially altered after adjustment for either limb length measure. 
Table 3 Associations between limb length measurements and dementia. Results are displayed as odds ratios (OR) with $95 \%$ confidence intervals

\begin{tabular}{lll}
\hline & $\begin{array}{l}\text { Dementia and demispan (OR } \\
\text { per } 5 \mathrm{~cm} \text { decrease) }\end{array}$ & $\begin{array}{l}\text { Dementia and leg length (OR } \\
\text { per } 5 \mathrm{~cm} \text { decrease) }\end{array}$ \\
\hline $\begin{array}{ll}\text { Unadjusted } \\
\text { Model 1 }\end{array}$ & $2.15(1.71$ to 2.71$)$ & $1.93(1.56$ to 2.39$)$ \\
Model $2 \dagger$ & $1.54(1.20$ to 1.96$)$ & $1.48(1.18$ to 1.87$)$ \\
Model 1-men & $1.45(1.13$ to 1.86$)$ & $1.42(1.12$ to 1.81$)$ \\
Model 1-women & $1.32(0.78$ to 2.29$)$ & $1.03(0.64$ to 1.65$)$ \\
Model 3ł-women & $1.95(1.32$ to 2.87$)$ & $1.80(1.29$ to 2.51$)$ \\
& $1.85(1.19$ to 2.88$)$ & $1.81(1.23$ to 2.65$)$
\end{tabular}

*Including age and education. †Including age, education, and APOE e4. łIncluding age, education, age at menarche, age at menopause.

Table 4 Associations between leg length $(5 \mathrm{~cm}$ decrease) and dementia subtypes*. Results are displayed as odds ratios with $95 \%$ confidence intervals

\begin{tabular}{lll}
\hline & Men & Women \\
\hline No cognitive impairment/dementia $(n=436)$ & 1.00 (reference) & 1.00 (reference) \\
Cognitive impairment, no dementia $(n=200)$ & $1.20(0.83$ to 1.72$)$ & $1.19(0.94$ to 1.52$)$ \\
All dementia $(n=110)$ & $1.02(0.63$ to 1.67$)$ & $2.61(1.68$ to 4.05$)$ \\
Alzheimer's disease $(n=87)$ & $1.02(0.56$ to 1.87$)$ & $2.49(1.57$ to 3.96$)$ \\
Vascular dementia $(n=15)$ & $1.20(0.44$ to 3.28$)$ & $4.58(1.11$ to 18.9$)$ \\
\hline *Adjusted for age and education. & &
\end{tabular}

Table 5 Multivariable analysis of the association between dementia and absence of formal education. Odds ratios with 95\% confidence intervals are displayed

\begin{tabular}{llll}
\hline & Total sample $(\mathrm{n}=746)$ & Men $(\mathrm{n}=308)$ & Women $(\mathrm{n}=438)$ \\
\hline Unadjusted & $6.05(3.59$ to 10.17$)$ & $3.64(1.63$ to 8.13$)$ & $8.36(3.54$ to 19.73$)$ \\
Adj for age & $4.73(2.76$ to 8.13$)$ & $2.85(1.25$ to 6.52$)$ & $6.63(2.70$ to 16.25$)$ \\
Adj for age + demispan & $3.89(2.20$ to 6.87$)$ & $3.13(1.34$ to 7.29$)$ & $6.13(2.46$ to 15.28$)$ \\
Adj for age + leg length & $4.08(2.28$ to 7.31$)$ & $3.33(1.41$ to 7.38$)$ & $5.66(2.26$ to 14.21$)$ \\
\hline
\end{tabular}

\section{DISCUSSION}

In a community sample of older people in Korea, dementia was associated with shorter arm and leg length, independent of age and education. The use of anthropometric measurements in adulthood as proxy measures for prenatal and childhood exposures has attracted increasing attention, particularly leg length. ${ }^{30}$ Longitudinal studies have found that leg length measured in childhood is more strongly associated with socioeconomic status than trunk length. ${ }^{12}$ Recent findings from a British cohort study, suggest that adult leg length is particularly sensitive to diet in infancy (under 5 years), specifically breast feeding and energy intake at age 4 (independent of birth weight) with trunk length more associated with factors (such as childhood serious illness and parental separation) operating over longer periods between infancy and puberty. ${ }^{19}$ Increasing population height (assumed to be secondary to improved nutrition in childhood) is also principally accounted for by increasing leg length rather than symmetrical increases in leg and trunk length. ${ }^{31}$ Older Korean people had shorter arm/leg measurements, consistent with this.

Shorter limb length was also associated with lower education. For these generations in Korea, access to education was strongly determined by a family's wealth. People with lower education would also have had increased exposure to other factors associated with poverty such as poor nutrition, infection, reduced access to medical care, and neglect. Limb length measurements were not associated with other putative measures of early life socioeconomic environment but these had not been formally validated and for some measures there was insufficient variation, as most people had grown up in a rural area with subsistence farming as the principal parental occupation. $^{32}$

Both measurements of limb length were associated with dementia after adjustment for age and education. A strength of the study was that cases and controls were drawn from a screened community population, using a structured diagnostic interview administered by trained local professionals, and consensus review. Government registration lists represent a highly inclusive sampling frame for epidemiological research in South Korea and a large proportion of the identified population participated in a preliminary interview. An important degree of differential attrition occurred before the dementia diagnostic interview. However, the strength of association between decreased education and cognitive impairment was not associated with attrition reducing the likelihood that the association between limb length and dementia arose through selection bias. Inaccuracies in dementia diagnosis or in limb length measurements would have obscured rather than exaggerated findings. While it is possible that measurements might have been systematically influenced by the presence of dementia, we feel that this is unlikely for the following reasons: (a) limb length measurements were easily applied, (b) no association was found between dementia and sitting height, (c) no associations were found between limb length and severity of dementia, (d) we can think of no reason why measurement error should occur to a different extent between male and female participants. We also know of no reason to suppose that these associations might have arisen through differential survival.

Prevalence rates of dementia were relatively high in this sample (15\%). Considering participation bias, even if there were no cases of dementia in non-participants, the prevalence 
rate in the source population would be $7 \%$, and still higher than that reported in a similarly aged Chinese population. ${ }^{33}$ Reasons for these differences have yet to be established. A higher ratio of Alzheimer's disease to vascular dementia was also found than that commonly reported from east Asian samples. Previous Korean studies have found prevalence rates for dementia of around $10 \%$, with $50 \%-60 \%$ of cases classified as Alzheimer's disease. ${ }^{34} 35$

If dementia is associated with shorter limb length, this will either be explained by shared genetic predisposition or a shared effect of the childhood environment. ${ }^{8}$ We know of no reason to suppose a genetic link but did not formally investigate this. Factors compromising full brain maturation in childhood may increase the risk of dementia by preventing full expression of structural and/or functional brain reserve. ${ }^{36}{ }^{37}$ The same factors may compromise other aspects of development such as skeletal growth. To our knowledge, no previous study has investigated the association between late life cognition and demispan or leg length. Findings however are consistent with reported associations between cognitive impairment/dementia and other skeletal measures, such as midlife height ${ }^{10}$ and head size. ${ }^{96}$ A limitation of this study is that no measurements were taken of head size. Associations between limb length and dementia might conceivably be entirely explained by intracranial volume, although we feel that this is unlikely.

The associations between limb length measurements (particularly leg length) and dementia were stronger in women than men. Although an a priori decision was made to stratify by sex, the finding should be treated as exploratory and requires replication. Height (and particularly growth between ages 15 and 26) was positively associated with cognitive function up to age 46 in a British longitudinal study. ${ }^{39}$ The gender interaction may be explained by different early life environments for male and female children of this generation. Male sex preference was highly prevalent at the time when participants were growing up, and it was common practice for parents to provide education and/or nutrition preferentially to male children, particularly in families with lower socioeconomic status. Lower education was also more strongly associated with dementia in women compared with men, supporting this.

Gender interaction might be explained by mediating health states later in life. Shorter limb length in Western populations is associated with cardiovascular risk factors, particularly those linked to the insulin resistance syndrome. ${ }^{40} 41$ Associations between decreased leg length and cardiovascular mortality were stronger for women than men in a British cohort. ${ }^{12}$ We found no associations between limb length and either hypertension or diabetes in this sample but vascular disease cannot be ruled out as a mediating pathway. A third explanation for sex differences might lie in lifetime oestrogen exposure. Associations between decreased leg length and later menarche are consistent with findings from prospective studies, ${ }^{42}$ although associations with later menopause are not consistent with lower early life cognitive function and earlier menopause found in a British cohort. ${ }^{43}$ Overall, however, we found little evidence to suggest that timing of menarche or menopause was a substantial mediating factor between limb length and dementia in women.

\section{ACKNOWLEDGEMENT}

The authors are very grateful for the advice of David Gunnell, Department of Social Medicine, Bristol University on preliminary findings.

\section{Authors' affiliations}

J-M Kim, Department of Psychiatry, College of Medicine, Chosun University, Kwangju, Republic of Korea

R Stewart, Section of Epidemiology, Institute of Psychiatry, London, UK I-S Shin, J-S Yoon, Department of Psychiatry and Research Institute of Medical Science, Chonnam National University Medical School,
Kwangiu, Republic of Korea

Funding: this study was supported by grants from the Ministry of Health and Welfare of Korea, and from Janssen Korea Ltd.

Competing interests: none declared.

\section{REFERENCES}

1 Mortimer JA, Graves AB. Education and other socioeconomic determinants of dementia and Alzheimer's disease. Neurology 1993;43:839-44

2 Stern Y, Gurland B, Tatemichi T K, et al. Influence of education and occupation on the incidence of Alzheimer's disease. JAMA 1994; 271:1004-10.

3 Liu HC, Fuh JL, Wang SJ, et al. Prevalence and subtypes of dementia in a rural Chinese population. Alz Dis Assoc Dis 1998;12:127-34.

4 Moceri VM, Kukull WA, Emmanuel I, et al. Early-life risk factors and the development of Alzheimer's disease. Neurology 2000;54;415-20.

5 Yano K, Grove JS, Masaki KH, et al. The effects of childhood residence in Japan and testing language on cognitive performance in late life among Japanese American Men in Hawaii. J Am Geriatr Soc 2000;48:199-204

6 Moceri VM, Kukull WA, Emmanuel I, et al. Using census data and birth certificates to reconstruct the early-life socioeconomic environment and the relation to the development of Alzheimer's disease. Epidemiology $2001 ; 12: 383-9$

7 Dekaban AS. Changes in brain weights during the span of human life: relation of brain weights to body heights and body weights. Ann Neurol 1978:4:345-56.

8 Rona RJ, Swan AV, Altman DG. Social factors and height of primary schoolchildren in England and Scotland. J Epidemiol Community Health 1978;32: 147-54

9 Schofield PW, Logroscino G, Andrews HF, et al. An association between head circumference and Alzheimer's disease in a population-based study of aging and dementia. Neurology 1997;49:30-7

10 Abbott RD, White LR, Ross GW, et al. Height as a marker of childhood development and late-life cognitive function: The Honolulu-Asia Aging Study. Pediatrics 1998;102:602-9.

11 Bannerman E, Reilly JJ, MacLennan WJ, et al. Evaluation of validity of British anthropometric reference data for assessing nutritional state of elderly people in Edinburgh: cross sectional study. BM 1997;315:338-41.

12 Gunnell D, Davey Smith G, Frankel S, et al. Childhood leg length and adulthood mortality: follow up of the Carnegie (Boyd Orr) Survey of Diet and Health in Pre-War Britain. J Epidemiol Community Health 1998;52: 142-52

13 10/66 Dementia Research Group. Dementia in developing countries. A consensus statement from the 10/66 Dementia Research Group. Int J Geriatr Psychiatry 2000;15:14-20.

14 Copeland JRM, Dewey ME, Griffiths-Jones HM. A computerized psychiatric diagnostic system and case nomenclature for elderly subjects: GMS and AGECAT. Psychol Med 1986;16, 89-99.

15 Yun DJ, Yun DK, Chang YY, et al. Correlations among height, leg length and arm span in growing Korean children. Ann Hum Biol 1995;22:443-58.

16 Bassey EJ. Demi-span as a measure of skeletal size. Ann Hum Biol 1986; 13:499-502.

17 Cockram DB, Baumgartner RN. Evaluation of accuracy and reliability of calipers for measuring recumbent knee height in elderly people. Am J Clin Nutr 1990:52:397-400.

18 van Leer EM, van Noord PA, Seidell JC. Components of adult height and height loss. Secular trend and effects of aging in women in the DOM project. Ann Epidemiol 1992;2:611-5

19 Wadsworth MEJ, Hardy RJ, Paul AA, et al. Leg and trunk length at 43 years in relation to childhood health, diet and family circumstances; evidence from the 1946 national birth cohort. Int J Epidemiol 2002;31:383-90.

20 Park JH, Kwon YC. Modification of the mini-mental state examination for use in the elderly in a non-western society: Part I. Development of Korean version of Mini-Mental State Examination. Int J Geriatr Psychiatry 1990:5:381-7.

21 Choi JY. Korean Dementia Rating Scale. Seoul: Hackjisa, 1988

22 Park JH, Park YN, Ko H J. Modification of the Mini-Mental State Examination for use in the elderly in a non-western society. Part II. Cut-off points and their diagnostic validities. Int J Geriatr Psychiatry $1991 ; 6: 875-82$

23 Mattis S. Mental status examination for organic mental syndrome in the elderly patient. In: Bellak L, Karasu T, eds. Geriatric psychiatry: a handbook for psychiatrists and primary care physicians. New York: Grune and Stratton, 1976:77-101.

24 Lawton MP, Brody EM. Assessment of older people: self-maintaining and instrumental activities of daily living. Gerontologist 1969;9:179-86.

25 Hughes CP, Berg L, Danziger WL, et al. A new clinical scale for the staging of dementia. Br J Psychiatry 1982;140:566-72.

26 Kim J-M, Prince M, Shin I-S, et al. Validity of Korean Form of Geriatric Depression Scale (KGDS) among cognitively impaired Korean elderly and development of a 15-item short version (KGDS-15). Int J Meth Psychiatr Res 2001;10:204-10.

27 American Psychiatric Association. Diagnostic and statistical manual of mental disorder. 4th edn. Washington DC: American Psychiatric Press, 1994. 
28 McKhann G, Drachman D, Folstein M et al. Clinical diagnosis of Alzheimer's disease: report of the NINCDS-ADRDA Work Group under the auspices of Department of Health and Human Services Task Force on Alzheimer's Disease. Neurology 1984;34:939-44.

29 Roman GC, Tatemichi TK, Erkinjuntti T, et al. Vascular dementia: diagnostic criteria for research studies. Report of the NINCDS-AIREN International Work Group. Neurology 1993:43:250-60.

30 Gunnell D. Can adult anthropometry be used as a 'biomarker' for prenatal and childhood exposures? Int J Epidemiol 2002;31:390-4.

31 Tanner JM, Hayashi T, Preece MA, et al. Increase in length of leg relative to trunk in Japanese children and adults from 1957 to 1977 comparison with British and with Japanese Americans. Ann Hum Biol 1982;9:411-23.

32 Kim J-M, Shin I-S, Yoon J-S, et al. Prevalence and correlates of late-life depression compared between urban and rural populations in Korea. Int J Geriatr Psychiatry 2002; 17:409-15.

33 Zhang $M$, Katzman R, Salmon D, et al. The prevalence of dementia and Alzheimer's disease in Shanghai, China: impact of age, gender, and education. Ann Neurol 1990;27:428-37.

34 Park J, Ko HJ, Park YN, et al. Dementia among the elderly in a rural Korean community. Br J Psychiatry 1994;164:796-801.
35 Woo JI, Lee JH, Yoo KY, et al. Prevalence estimation of dementia in a rural area of Korea. J Am Geriatr Soc 1998;46:983-7.

36 Snowdon DA, Kemper SJ, Mortimer JA, et al. Linguistic ability in early life and cognitive function and Alzheimer's disease in late life. JAMA 1996;275:528-32

37 Schmand B, Smit JH, Geerlings MI, et al. The effects of intelligence and education on the development of dementia. A test of the brain reserve hypothesis. Psychol Med 1997;27:1337-44.

38 Reynolds MD, Johnston JM, Dodge HH, et al. Small head size is related to low Mini-Mental State Examination scores in a community sample of nondemented older adults. Neurology 1999;53:228-9.

39 Richards M, Hardy R, Kuh D, et al. Birthweight, postnatal growth and cognitive function in a national UK birth cohort. Int J Epidemiol 2002;31:342-8.

40 Davey Smith G, Greenwood R, Gunnell D, et al. Leg length, insulin resistance, and coronary heart disease risk: the Caerphilly Study. J Epidemiol Community Health 2001:55:867-72.

41 Han TS, Hooper JP, Morrison CE, et al. Skeletal proportions and metabolic disorders in adults. Eur J Clin Nutr 1997;51:804-9.

42 dos Santos Silva I, De Stavola BL, Mann V, et al. Prenatal factors, childhood growth trajectories and age at menarche. Int J Epidemiol 2002;31:405-12.

43 Richards M, Kuh D, Hardy R, et al. Lifetime cognitive function and timing of the natural menopause. Neurology 1999;53:308-314.

\section{HISTORICAL NOTE}

\section{A note on Hoover's sign}

$\mathrm{H}$ oover's $\operatorname{sign}^{1}$ is a manoeuvre aimed to separate organic from nonorganic paresis of the leg. The sign relies on the principle of synergistic contraction. Involuntary extension of the "paralysed" leg occurs when flexing the contralateral leg against resistance. It has been neglected, although it is a useful clinical test.

The patient lies supine, the examiner's hand is placed under the non-paralysed heel, and the patient is asked to elevate the paralysed leg. In organic paresis the examiner feels a downward pressure under the non-paralysed heel; in malingering no pressure is felt. However, some have used it in a less precise context as a sign of pain or weakness in the back or lower extremities. ${ }^{2}$ The reliability has been questioned in one study because of poor pelvic stabilisation and varying levels of pain, effort, and spasticity. ${ }^{3}$

Charles Franklin Hoover (1865-1927) was an American physician born in Cleveland, Ohio, who read medicine at Harvard. He worked in Vienna under Neusser, and in Strasburg with F Kraus before returning to Cleveland. He was appointed Professor of Medicine in 1907. His main interests were in diseases of the diaphragm, lungs, and liver.
Another Hoover's sign is inward movement of the lower rib cage during inspiration, implying a flat, but functioning, diaphragm.

J M S Pearce

304 Beverley Road, Anlaby, Hull HU1O 7BG, UK; email: jmspearce@freenet.co.uk

\section{References}

1 Hoover CF. A new sign for the detection of malingering and functional paresis of the lower extremities. JAMA 1908:51:746-7.

2 Arieff, A, Tigay El, Kurtz JF, et al. The Hoover sign: an objective sign of pain and/or weakness in the back or lower extremities. Arch Neurol 1961;5:673-8.

3 Archibald, KC, Wiechec, F. A reappraisal of Hoover's test. Arch Phys Med Rehabil 1970;51:234-8 